\title{
Nonlinear Exchange Rate Pass-Through : Does Business Cycle Matter?
}

\author{
Nidhaleddine Ben Cheikh \\ ESSCA School of Management, Angers, France \\ Younes Ben Zaied \\ ESSEC Business School, Cergy-Pontoise, France \\ Houssam Bouzgarrou \\ University of Sousse - ISG, Sousse, Tunisia \\ Pascal Nguyen \\ ESDES, The Business School of UCLy, France
}

\begin{abstract}
This paper investigates the nonlinear dynamics in the Exchange Rate PassThrough of the Euro area. We implement the class of logistic smooth transition models to explore the role of the business cycle in driving nonlinearity. Using quarterly data over the period of January $1980 \sim$ April 2015, our results provide strong evidence of nonlinearity in 7 out of 10 Eurozone countries. We show that the exchange rate transmission to inflation respond to the economic activity in the nonlinear manner, that is, exchange rate pass-through is higher during expansion than recession periods. By monitoring the different patterns of growth and exchange rate pass-through, European monetary authorities could enhance inflation convergence within the Euro area.
\end{abstract}

\footnotetext{
* Corresponding Author: Nidhaleddine Ben Cheikh; ESSCA School of Management, 1 Rue Lakanal, 49000 Angers, France, Tel: +33 174345278, Fax: +33 241735710, E-mail: nbcheikh@gmail.com.

Co-authors: Younes Ben Zaied; ESSEC Business School, 3 Avenue Brenard Hirsch, 95021 Cergy-Pontoise, France, Tel: +33 134433000, Fax: +33 134433001, E-mail: benzaied@essec.edu;

Houssam Bouzgarrou; University of Sousse - ISG, Rue Abdlaaziz il Behi, 4000 Sousse, Tunisia, Tel: +216 73332976, Fax: +216 73332978, E-mail: h.bouzgarrou@hotmail.fr;

Pascal Nguyen; ESDES, The Business School of UCLy, 10 Place des Archives, 69002 Lyon, France, Tel: +33 426844934, Fax: +33 472325048, E-mail: pnguyen@univ-catholyon.fr.
} 
JEL Classifications: C22, E31, F31

Keywords: Exchange Rate Pass-Through, Business Cycle, Euro Area, Smooth Transition Regression Models

\section{Introduction}

The Exchange Rate Pass-Through (ERPT), defined as the degree to which exchange rate changes are reflected in domestic prices, is a noteworthy international macroeconomic issue that policymakers should gauge accurately. In spite of its relevance, there are few studies that explore nonlinear behavior in the pass-through mechanism ${ }^{1}$. Extant literature describes the nature of exchange rate shocks in driving nonlinearities. On the one hand, nonlinearity is tested with respect to the direction of currency movements, whether ERPT responds asymmetrically to episodes of appreciation and depreciation. On the other hand, some studies emphasize the size of exchange rate changes as a potential source of nonlinearities, whether the ERPT is higher for large exchange rate changes than for small ones (Ben Cheikh 2012).

Besides, only a few empirical studies hypothesize that there is a nonlinear relationship between ERPT and inflation. For example, Shintani et al. (2013) found a strong positive correlation between ERPT and inflation in the United States (US) economy. Their results reveal that the degree of ERPT becomes large when the inflation rate rises above $2 \%$. This latter result is in line with Taylor (2000) who argued that the shift toward a low and stable inflation regime entails a decline in the degree of ERPT in many industrialized countries. In fact, inflation levels are currently low and stable in the developed countries, and even in some emerging markets (Ca'Zorzi et al. 2007) $)^{2}$. Therefore, it is important to raise the question of whether other sources of nonlinearity could drive the extent of pass-through.

This paper focuses on the case of the Euro area, where the single currency has experienced strong fluctuations since its inception on January 1, 1999. For example, during the first three years of its existence, the euro experienced a large depreciation of roughly 45 percent against the

\footnotetext{
${ }^{1}$ As discussed by Marazzi et al. (2005), previous studies provide mixed results, with no clear support for the existence of important nonlinearities.

${ }^{2}$ For the case of Taiwan, Lin and Wu (2012) confirmed that a weak degree of pass-through is found in the low positive inflation environment. However, once the importing country enters a deflation regime, there is a rebound in ERPT, which becomes inversely higher.
} 
US dollar and about 25 percent on a trade-weighted basis. This extensive depreciation was followed by roughly the same magnitude of appreciation between 2002 and 2004. In addition, some Euro area members experienced persistent inflation differentials during almost the entire decade after the inception of the euro. As explained by Andersson et al. (2009), the main factor behind the Eurozone inflation differentials are differences in business cycle positions. In addition to the global financial crisis of $2007 \sim 2008$ and the ensuing Euro crisis, there have been indications of divergence in growth patterns and less synchronized business cycles. Thus, it is important to investigate whether economic activity along the business cycle influences the relationship between the exchange rate and inflation. The dynamic behavior of pass-through is driven by economic output, which can be modeled in a nonlinear way.

Hence, this study examine whether there is a nonlinear relationship between ERPT and the business cycle. To achieve this goal, we implement nonlinear regime-switching models that account for policy shifts within the monetary union. Within this class of models, the presence of nonlinearity is tested and potential nonlinear behavior is captured endogenously from the dataset ${ }^{3}$. There has been a myriad of studies conducted about the extent of pass-through in the Eurozone members. However, none have introduced possible nonlinearities in the estimation of ERPT with respect their growth patterns (Comunale and Kunovac 2017, 2017, Özyurt, 2016, for recent empirical literature). Moreover, most of the empirical works dealing with nonlinearity have used nonlinear threshold models where the transition across regimes is abrupt (Aleem and Lahiani 2014, Donayre and Panovska 2016). Indeed, there is wide heterogeneity across foreign firms in their pricing strategies toward the state of the economy in the importing country. Thus, at the aggregate level, considering the transition across regimes as gradual would be more realistic. We propose another class of nonlinear regime-switching models, namely, the Smooth Transition Regression (STR), where the transition between states is rather smooth. The model is estimated for 10 Euro area countries (Austria, Belgium, Germany, Spain, France, Greece, Ireland, Italy, Luxembourg, and Portugal), using quarterly data over the period of January $1980 \sim$ April 2015. We focus on the pass-

${ }^{3}$ For instance, to capture nonlinear or asymmetric behavior in pass-through, some empirical studies have estimated standard linear models augmented with interactive dummy variables. 
through to consumer price inflation by raising the question of whether the business cycle constituting a source of nonlinearity.

The remainder of the paper is structured as follows: Section II gives an overview of the nonlinear mechanism in ERPT. Section III presents the empirical approach and the data. The main empirical results are discussed in Section IV and Section V concludes.

\section{Nonlinearities in ERPT}

The presence of nonlinear mechanisms in the extent of pass-through has been linked to the state of inflation in the importing country as ERPT is found to be lower in periods of low inflation (Shintani et al. 2013, Ben Cheikh and Louhichi 2016, Aleem and Lahiani 2014). This strand shows that the degree of pass-through responds nonlinearly to inflation. That is, ERPT becomes higher when the inflation level surpasses some limit. These findings are in line with Taylor (2000) who postulated that a prevailing lowinflation environment, which serves to reduce the perceived persistence of cost shocks, lowers the degree of ERPT. Moreover, given foreign firms' pricing behavior, a stable inflation environment in the destination country may lead exporters to follow a Local-Currency Pricing (LCP) strategy. In this case, exporting firms would adjust their markups in response to currency changes, thus leading to a lesser extent of pass-through. However, when the importing country is experiencing higher inflation rates, exporters would change their pricing decision by adopting a Producer-Currency Pricing (PCP) strategy. In this case, the effect of exchange rate changes is fully transmitted into prices.

Following the firm pricing behavior literature, ERPT may also vary according to other macroeconomic factors in the destination country, such as the level of economic activity. It is expected that when the economy is booming, ERPT would be higher than in periods of slowdown. Exporting firms would find it easier to pass-through exchange rate changes when the economy is growing fast, rather than when it is in a recession and its sales are already falling. Within a panel data framework for 71 countries, Goldfajn and Werlang (2000) reported an asymmetric reaction of ERPT over the business cycle; that is, currency changes have a higher impact on prices in periods of 
expansion. This result was confirmed by Correa and Minella (2006) using a nonlinear threshold model for the Brazilian economy. They suggested that when the output gap is above a certain threshold, ERPT becomes higher. Along the same line, Donayre and Panovska (2016) used a Bayesian Threshold Vector Autoregression (TVAR) to study the relationship between ERPT and economic activity in Canada and Mexico. Their results provide evidence of nonlinear regime dependence of pass-through depending on the state of the economy, in the sense that ERPT rates are higher when the growth rate of output is large.

In fact, the empirical literature is not conclusive about the direction of the relationship between ERPT and the business cycle. As explained by McCarthy (2007), aggregate demand shifts (which will be proxied by the output gap) in conjunction with exchange rate fluctuations, can alter the profit margins in an imperfectly competitive environment, leading to reduced passthrough. Then, in countries where aggregate demand is more volatile, ERPT tends to become lower. Using standard Vector Autoregressive (VAR) models for nine industrial countries, McCarthy (2007) revealed that less volatile GDP is associated with a larger pass-through of exchange rates to domestic inflation, although such relationships are short-lived for consumer price inflation. A better understanding is of particular importance in the light of the recent Great Recession and the Euro area sovereign debt crisis. The level of economic activity across Euro member states exhibited divergent growth patterns with several switches between boom-bust episodes, including the period prior 2007 2008. Policymakers should be able to gauge how boombust episodes are connected to the extent of pass-through for an accurate monetary policy reaction. In a recent study, Jašová et al. (2015) investigated whether exchange rate transmission has changed since the global financial crisis. They found that there has been a decrease in the ERPT coefficients for emerging economies, whereas for advanced economies, the exchange rate effects have remained low. They argued that the lower pass-through in emerging markets would imply that the exchange rate channel of monetary policy might be less effective to affect inflation after the financial crisis. As well-known, a decline in pass-through would imply more synchronized business cycles across countries ${ }^{4}$.

\footnotetext{
${ }^{4}$ As shown by Betts and Devereux (2001), when pass-through is complete, monetary policy shocks produce a negative co-movement of output across countries.
} 
Given the tight relationship between business cycle positions and inflation differentials within the Eurozone, there might be a positive feedback loop in the sense that a higher degree of business cycle synchronization could, in turn, enhance price convergence within the monetary union.

Finally, it is worth highlighting that a relevant econometric approach is required when dealing with these different policy shifts and regimeswitching behaviors in the economic variables. This paper proposes to implement the class of STR models where the nonlinear dynamic could be modeled properly from the datasets. To the best of our knowledge, there are very few studies following this methodology to estimate the extent of pass-through. For example, Nogueira Jr. and Leon-Ledesma (2008) used the STR model to capture nonlinearity with respect to the business cycle in a sample of six developed and developing Inflation Target countries 5 . Unlike the existing literature, our paper deals with the Euro area case as we expect that the different macroeconomic developments experienced by the monetary union members would generate a nonlinear mechanism in ERPT.

\section{Econometric Approach}

\section{A. Nonlinear smooth transition framework}

To examine the nonlinear dynamic of the degree of ERPT, an appropriate econometric methodology should be implemented. Among the various regime-switching models, the STR framework enables to capture the changing behavior in the data series, such as exchange rates and prices (Ben Cheikh and Rault, 2016b). One of the key features of the STR models is to allow for pass-through elasticities to vary across different economic regimes. The STR model takes the following general form:

$$
y_{t}=\beta_{1} x_{t}+\beta_{2} x_{t} G\left(s_{t} ; \gamma, c\right)+\varepsilon_{t}
$$

${ }^{5}$ Similarly, for the case of Finland, Ben Cheikh and Rault (2016a) found a positive relationship between the economic cycle and ERPT. For the case of our study, the Finnish economy is not included in the sample of Euro area member states. 
where $s_{t}$ is the transition variable, $\gamma$ measures the speed of transition from one regime to the other, $c$ is the threshold for the transition function, and $G\left(s_{t} ; \gamma, c\right)$ is the transition function depending on the values taken by all these parameters. Different specifications can be considered for the transition function. There are different possible choices for the transition functions. Of the most used functions are the exponential and logistic forms. The transition logistic function can be presented as follows:

$$
G\left(s_{t} ; \gamma, c\right)=\left[1+\exp \left\{-\gamma\left(s_{t}-c\right)\right\}\right]^{-1}
$$

Under the logistic transition function, Equation (1) corresponds to the Logistic Smooth Transition Regression (LSTR) model. The implied nonlinear dynamics in the LSTR specification depends on whether the transition variable is below or above the level of threshold $c$. In other words, the parameters of the model changes monotonically from $\beta_{1}$ to $\left(\beta_{1}+\beta_{2}\right)$ as $s_{t}$ increases. Indeed, if $\left(s_{t}-c\right) \rightarrow-\infty$ and $G\left(s_{t} ; \gamma, c\right) \rightarrow 0$, then the model's coefficient corresponds to $\theta_{l}$. If $\left(s_{t}-c\right) \rightarrow+\infty$ and $G\left(s_{t} ; \gamma, c\right) \rightarrow 1$, then the coefficient becomes $\left(\beta_{1}+\beta_{2}\right)$. Finally, if $s_{t}=c$ and $G\left(s_{t} ; \gamma, c\right)=0.5$, then the coefficient will be equal to $\left(\beta_{1}+\beta_{2} / 2\right)$.

An alternative choice of transition function, which is also considered in the STR literature, is the exponential specification $G\left(s_{t} ; \gamma, c\right)=1-\exp \left\{-\gamma\left(s_{t}-c\right)^{2}\right\}$. In this case, Equation (1) corresponds to the so-called Exponential STR (ESTR) model and the implied nonlinear dynamic will be different from the logistic specification. Within the ESTR model, nonlinear coefficient changes depend on whether $s_{t}$ is in the neighborhood or far away from the threshold, regardless of whether $\left(s_{t}-c\right)$ is positive or negative.

In this paper, we pretend that consumer price inflation responds to exchange rate changes in a nonlinear manner. Precisely, the extent of ERPT is assumed to respond nonlinearly to the economic activity along the business cycle, meaning that ERPT would be greater in periods of prosperity than in periods of slowdown. As discussed in van Dijk et al. (2002), LSTR would be appropriate for modeling business cycle asymmetry where dynamic behavior is different during expansion vs. recession. If we consider the output growth as a transition variable $s_{t}$ with threshold value $c \simeq 0$, then the LSTR model would capture episodes of positive and negative growth. Thus, a LSTR specification would be more relevant in describing this asymmetric and 
dynamic behavior between negative and positive deviations of the transition variable $s_{t}$ from the threshold level $c$.

As explained by Teräsvirta (1994), nonlinear models such as STR models, require a careful and systematic modeling strategy. The modeling procedure consists of the following three steps: specification, estimation, and evaluation. First, we test for nonlinearity by selecting the appropriate threshold variable $s_{t}$, and deciding for the appropriate specification of the transition function. Next, using the Nonlinear Least Squares (NLS) estimation technique, the parameters in the selected STR model are estimated. The estimation stage involves finding appropriate starting values for the nonlinear estimation. A standard practice in the STR literature is to construct a grid search for estimating $\gamma$ and $c$. For each value of $\gamma$ and $c$, the residual sum of squares is computed. The starting values selected in the NLS procedure are those that minimized the residual sum of squares ${ }^{6}$. Finally, at the evaluation stage, the estimated model should be subjected to misspecification tests as in the case of linear models. In this section, we evaluate the properties of the fitted models using the following diagnostic tests: LM test of no error autocorrelation; LMtype test of no ARCH; Jarque-Bera normality test; LM test of no remaining nonlinearity; and LM-type test of parameter constancy (Eitrheim and Teräsvirta 1996).

\section{B. Model and data}

In our empirical analysis, we define a nonlinear pass-through equation that includes an extension of the standard ERPT model. To test whether ERPT responds nonlinearly to the business cycle, the equation to estimate has the following form:

$$
\begin{gathered}
\Delta c p i_{t}=\alpha+\sum_{j=1}^{N} \lambda_{j} \Delta c p i_{t-j}+\sum_{j=0}^{N} \psi_{j} \Delta y_{t-j}+\sum_{j=0}^{N} \delta_{j} \Delta w_{t-j}^{*} \\
+\sum_{j=0}^{N} \beta_{j} \Delta e_{t-j}+\left(\sum_{j=0}^{N} \phi_{j} \Delta e_{t-j}\right) G\left(s_{t} ; \gamma, c\right)+\varepsilon_{t}
\end{gathered}
$$

\footnotetext{
${ }^{6}$ As explained by Teräsvirta (1994), if the speed of transition $\gamma$ is not a scale-free parameter, then it has to be divided by the standard deviation of the transition variable $S_{t}$.
} 
where $\Delta c p i_{t}$ is the Consumer Price Index (CPI) inflation rate, $\Delta e_{t}$ is the nominal exchange rate changes, $\Delta y_{t}$ is the output growth used to capture changes in domestic demand conditions, and $\Delta w_{t}^{*}$ is the changes in foreign producer cost. For our case, the economic activity is considered as a transition variable $S_{t}=\Delta y_{t-j}$ in Equation (3).

According to (3), we can compute a time-varying ERPT elasticity as follows:

$$
E R P T=\beta_{0}+\phi_{0} G\left(\Delta y_{t-j} ; \gamma, c\right)
$$

The ERPT coefficient takes different values depending on whether the transition variable $s_{t}$ is below or above the threshold value ${ }^{7}$. If $\left(\Delta y_{t-j}-c\right) \rightarrow-\infty$, i.e., the economic output is under the threshold, then ERPT coefficient is equal to $L R E R P T=\beta_{0}$. This corresponds to the pass-through elasticity during a low-activity regime, i.e., when $\left.G\left(\Delta y_{t-j} ; \gamma, c\right)=0\right)$. However, If $\left(\Delta y_{t-j}-c\right) \rightarrow+\infty$, i.e., the economic activity is above the threshold, the pass-through coefficient becomes ERPT $=\beta_{0}+\phi_{0}$. The latter corresponds to the degree of pass-through during a high-activity regime when $G\left(\Delta y_{t-j} ; \gamma, c\right)=1$.

Our nonlinear Equation (3) is estimated for 10 Euro area countries (Austria, Belgium, Germany, Spain, France, Greece, Ireland, Italy, Luxembourg, and Portugal), using quarterly data spanning over the period of January1980 to April 2015. All data are taken from the OECD's Economic Outlook database except for exchange rate series, which are obtained from International Financial Statistics of the International Monetary Fund. Our dependent variable represents the quarterly change in the CPI. Output growth is constructed using the rate of growth of real GDP. The nominal exchange rate is defined as domestic currency units per unit of foreign currency, which implies that an increase represents a depreciation for the importing country. Finally, to capture changes in foreign costs, we consider an exporter partners' cost proxy in the spirit of Campa and Goldberg (2005) and Bailliu and Fujii (2004). Thus, the foreign producer cost can be expressed in logarithms as $w_{t}{ }_{t} \equiv q_{t}+u l c_{t}-e_{t}$, where $q_{t}$ is the Unit Labor Cost (ULC) based on the real effective exchange rate, $u l c_{t}$ is the ULC in the domestic country, and $e_{t}$

\footnotetext{
${ }^{7}$ It is possible to define long-run ERPT elasticity as . [ $\left.\sum_{j=0}^{N} \beta_{j}+\sum_{j=0}^{N} \phi_{j} G\left(s_{i} ; \gamma, c\right)\right] /\left(1-\sum_{j=1}^{N} \lambda_{j}\right]$ One major drawback of this measure is its sensitivity to the number of lags introduced in the model, leading to inaccurate long-run elasticity. Hence, in this paper, we focus solely on the short-run pass-through.
} 
the nominal effective exchange rate. The lag length of the variables entering Equation (3) is determined in line with van Dijk et al.'s (2002) strategy. We follow a general-to-specific approach to select the final specification. We start with a model having a maximum lag length of $N=4$ and then sequentially drop the lagged variables for which the $t$-statistic of the corresponding parameter is less than 1.0 in absolute value ${ }^{8}$.

\section{Empirical Results}

As it is crucial to control for nonlinearities when estimating the degree of pass-through, we investigate here whether the business cycle affects the mechanism in a nonlinear way. During an economic slowdown, currency variation will have a smaller impact on domestic price, whereas when the economy is booming, the ERPT is found to be greater. In fact, firms are more likely to increase their prices during periods of high economic activity, when they typically face increasing sales. By contrast, if the economy is sluggish, depreciation shocks may leave prices unchanged as firms will opt to reduce markups in order not to lose market share. For instance, Garcia and Restrepo (2001) corroborated this view for the case of Chile as they revealed a positive dependence of ERPT to the economic cycle. Their results indicate that the negative output gap experienced by the Chilean economy in the 1990s had offset the inflationary impact of exchange rate depreciation by reducing firms' margins.

To further highlight the presence of linearities, our empirical specification introduces economic output as a driving factor in the nonlinear dynamic. The rate of growth of real GDP is taken as a measure at a certain phase of the economy's business cycle ${ }^{9}$. Thus, lagged real GDP growth is considered as the transition variable $\left(S_{t}=\Delta y_{t-j}\right)$ in the STR model. When its values

\footnotetext{
${ }^{8}$ Individual series in-level are non-stationary according to the efficient unit root test suggested by Elliott et al. (1996). Due to the possible presence of regime shifts, Lumsdaine and Papell's (1997) unit root tests, allowing for two structural breaks under the alternative hypothesis, are also conducted and confirm the non-stationarity of variables in-level. We then tested for the presence of a cointegrating relationship between variables (in levels) entering the pass-through equation using Gregory and Hansen's (1996) cointegration test, which explicitly incorporates a break in the cointegrating relationship. Our results reveal that variables are not cointegrated. Results are available upon request. Consequently, log differences of the variables are used in the estimation of the LSTR pass-through equation given in Equation (3). ${ }^{9}$ The output gap is used as an indicator for the economic activity as for the cases in Goldfajn and Werlang (2000) and Correa and Minella (2006). However, it is possible that the use of the output gap would eliminate some valuable information from the real GDP data series. As recommended by Nogueira Jr. and Leon-Ledesma (2008), the real output growth would be more appropriate to proxy the economic activity within an STR model.
} 
exceed an estimated threshold, these can be interpreted as periods of expansion, whereas when values are below the threshold, these are periods of economic slowdown or recession. The selection of an adequate lagged real GDP growth as a transition variable is achieved by means of linearity tests. The linearity tests are conducted for each lagged output growth $\Delta y_{t-j}$ with $j=1,2,3,4$.

To construct the linearity test, Teräsvirta (1994) suggested approximating the logistic function (2) in (1) by a third-order Taylor expansion around the null hypothesis $\gamma=0$. The resulting test has power against both the LSTR and ESTR models. Assume the transition variable $S_{t}$ is an element in $x_{t}$ and let $x_{t}=\left(1, \tilde{x}_{t}^{\prime}\right)$, where $\tilde{x}_{t}^{\prime}$ is an $(m \times 1)$. Taylor approximation yields the following auxiliary regression:

$$
y_{t}=\alpha_{0}^{\prime} x_{t}+\sum_{j=1}^{3} \alpha_{j}^{\prime} \tilde{x}_{t}^{\prime} s_{t}^{j}+u_{t}^{*} \quad(t=1, \ldots, T)
$$

where $u_{t}^{*}=u_{t}+R_{3}\left(\gamma, c, s_{t}\right) \theta_{2} x_{t}$, with $R_{3}\left(\gamma, c, s_{t}\right)$ the residual of Taylor expansion. The null hypothesis of linearity is $H_{0}$; i.e., $\alpha_{1}=\alpha_{2}=\alpha_{3}=0$. van Dijk et al. (2002) suggested the use of $F$-versions of the LM test statistic, which has an approximate $F$-distribution with $3 m$ and $T-4 m-1$ degrees of freedom under $H_{0}$. Linearity tests are executed for each of the potential transition variables, which are lagged water price changes in our case. Once linearity has been rejected, one has to choose whether a logistic or exponential function should be specified. The choice between these two types of models is based on the auxiliary regression (5). Teräsvirta (1994) suggested that this choice can be based on testing the following sequence of nested null hypotheses:

1. Test $H_{04}: \alpha_{3}=0$

2. Test $H_{03}: \alpha_{2}=0 \mid \alpha_{3}=0$

3. Test $H_{02}: \alpha_{1}=0 \mid \alpha_{2}=\alpha_{3}=0$ 
The decision rule is the following: if the $H_{03}$ test yields the strongest rejection measured in the $p$-value, then the ESTR model is selected. Otherwise, the LSTR model is preferred. Table 1 provides the $p$-values of the $F$-version of the LM test with the different lags for the output growth $\Delta y_{t-j}$. In the first row, we report the test of the null hypothesis of linearity against the alternative of STR nonlinear model. The following rows in Table 1 show the sequence of null hypotheses for choosing the LSTR or ESTR model.

According to the linearity test results in Table 1, there is strong evidence of nonlinearities in 7 out of 10 member states, except for France, Ireland, and Luxembourg. This confirms the presence of regime-switching behavior in the ERPT equation, which is driven by output growth. Once linearity has been rejected, the sequence of nested null hypotheses is conducted to choose the adequate transition function, i.e., logistic or exponential. As explained before, the economic intuition must be also considered in our choice of the relevant STR specification. According to Van Dijk et al. (2002), LSTR models are more appropriate in describing processes whose dynamic properties are different in periods of expansion than what they are during a recession. Therefore, the ERPT may be different depending on whether economic activity is above or below a given threshold. In other words, the exchange rate changes would have a higher pass-through when the economy is growing faster than when the output growth is below the threshold. Thus, given these features, the LSTR model is preferred to ESTR. Estimation results from the LSTR pass-through Equation (3) are summarized in Table 2. We report only Euro area countries rejecting the null of linearity (7 out of 10 countries). In addition to the estimated threshold level and the speed of transition, we report ERPT coefficients for the two extreme regimes, i.e., low and high activity (when $G\left(s_{t} ; \gamma, c\right)=0$ and $G\left(s_{t} ; \gamma, c\right)=1$, respectively) as defined in Equation (4). ${ }^{10}$ 


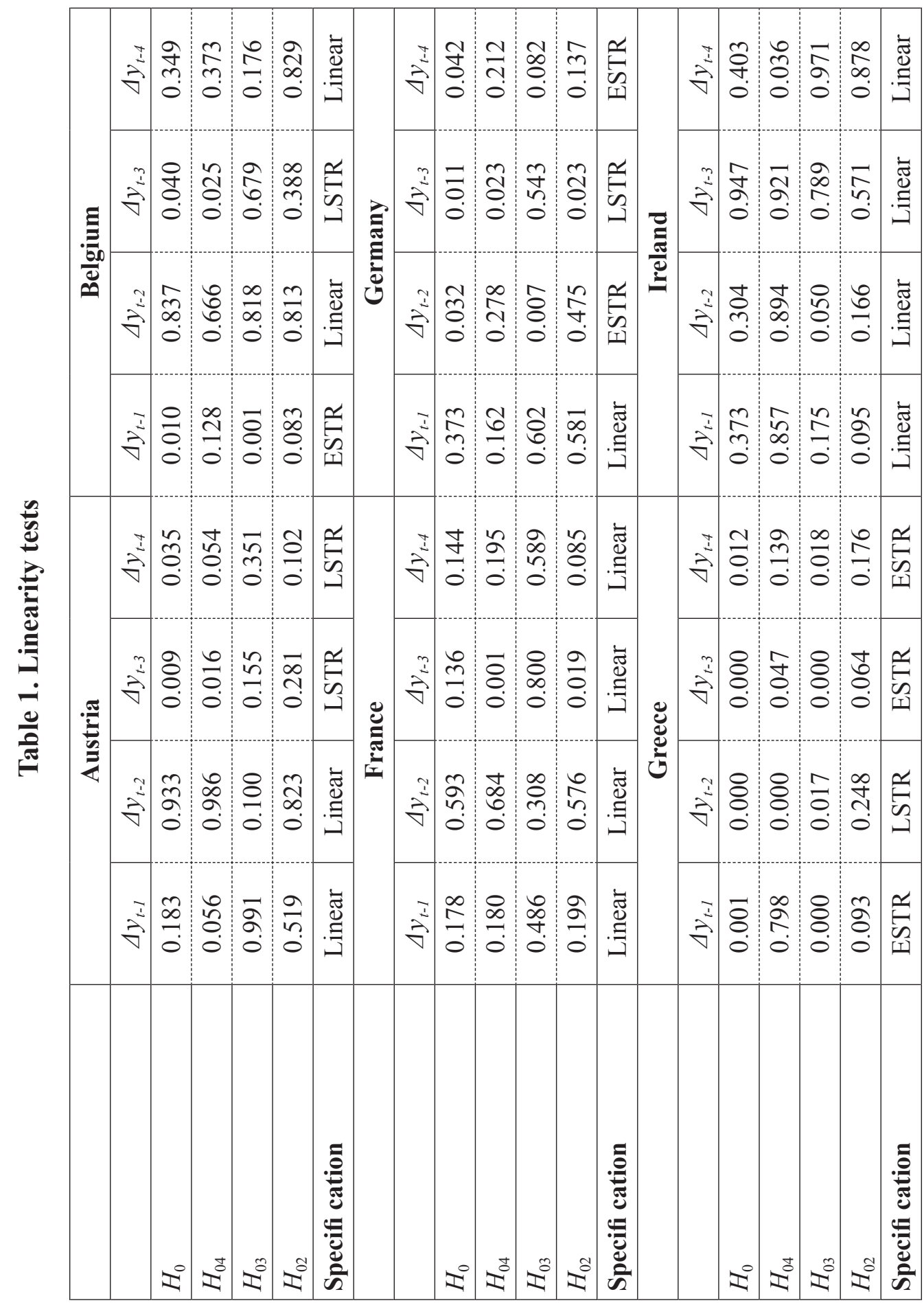




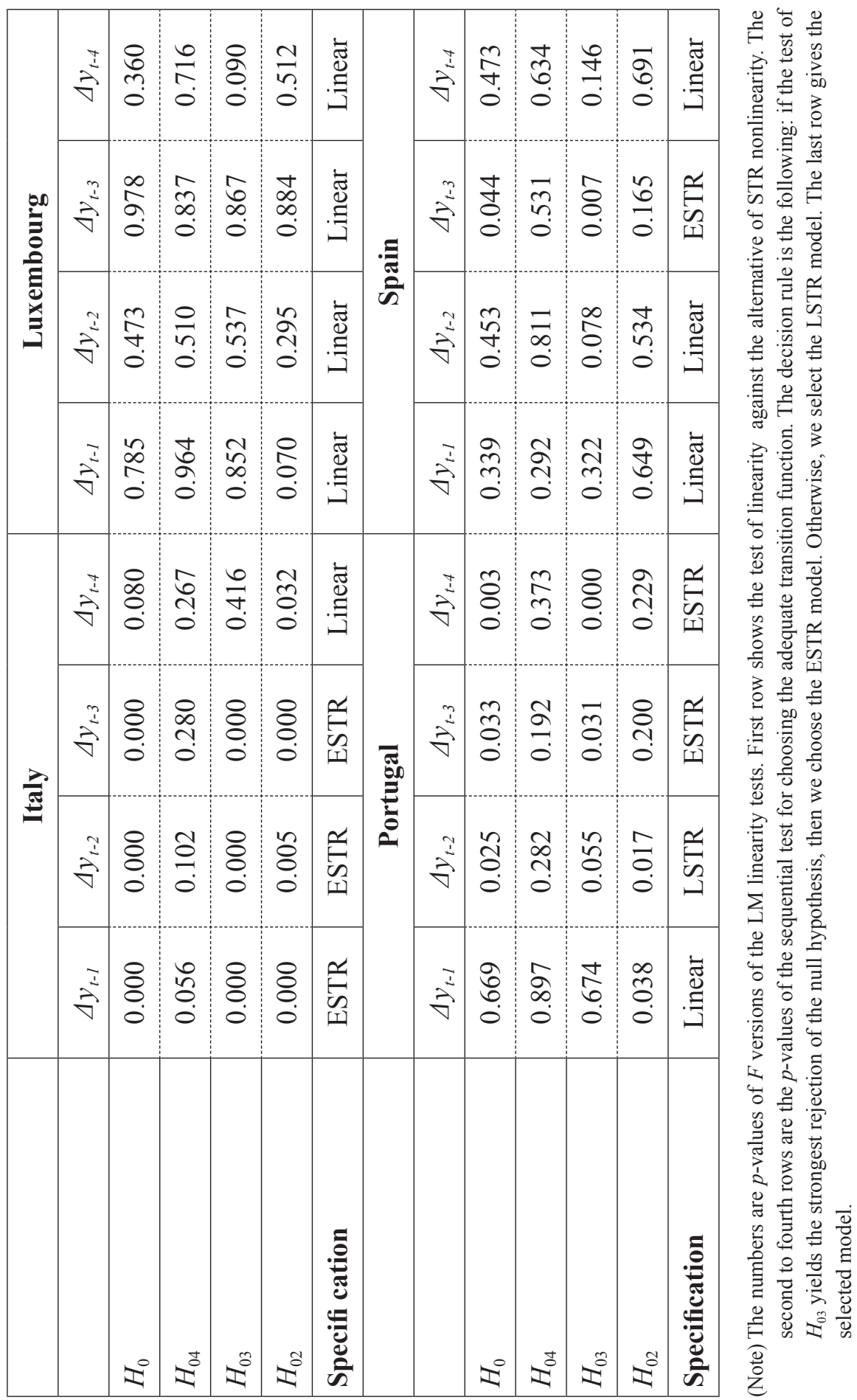


We compute the Sum of Squared Residuals Ratio $\left(S S R_{\text {ratio }}\right)$ between the LSTR model and the linear specification that suggests a better fit for the nonlinear model. We also check the quality of the estimated LSTR models by conducting several misspecification tests. In most of cases, the selected LSTR models pass the main diagnostic tests, i.e., no error autocorrelation, no conditional heteroscedasticity, parameters constancy, and no remaining nonlinearity. According to Table 2, threshold values of real GDP growth are significant and vary considerably across our sample countries, ranging from $0.3 \%$ in Belgium to $4 \%$ in Austria. Concerning pass-through estimates, there are four out of seven Eurozone countries showing significant nonlinear ERPT with respect to business cycle. In other words, pass-through elasticity is significantly different between low and high activity regimes in four Euro members. In addition, we denote that the extent of passthrough depends positively on economic activity for three Eurozone countries, namely, Austria, Germany, and Spain. For these countries, the exchange rate transmission to CPI inflation is significantly greater when output growth is above some threshold. For instance, the pass-through coefficient in Germany is $0.02 \%$, which is not significantly different from zero when GDP growth is below $1 \%$, i.e., during an economic slowdown. However, when the German economy is growing faster-above the threshold of $1 \%$-ERPT elasticity increases to about $0.13 \%$.

Our results corroborate the findings of Correa and Minella (2006) and Przystupa and Wróbel (2011) who suggested that when the output gap is above a certain threshold, ERPT becomes higher. For the case of Brazil, Correa and Minella (2006) found that pass-through is not statistically different from zero in the economic slowdown regime, whereas it is around 9\% when economic activity is higher. Similarly, for the Polish economy, Przystupa and Wróbel (2011) showed a clear difference in ERPT between the periods of prosperity and slump. The response of inflation is equal to 0.27 for expansion episodes, whereas it is reduced to 0.09 when the economy is contracting. In the same line, Donayre and Panovska (2016) studied the relationship between ERPT and economic activity in Canada and Mexico. Using a TVAR framework, they report that ERPT coefficients for the Mexican economy are around $4 \%$ in the low-growth regime and $7.5 \%$ in the high-growth regime one year after a shock. It is noteworthy that despite the large decline in the inflation environment following the introduction of an inflation targeting regime, Mexico is still experiencing high ERPT, particularly on import prices. This means that the evolving level of economic activity contributes significantly in driving the exchange rate transmission. 
Table 2. Estimated ERPT elasticities from the LSTR model

\begin{tabular}{|c|c|c|c|c|c|c|c|}
\hline & Austria & Belgium & Germany & Greece & Italy & Portugal & Spain \\
\hline $\begin{array}{l}\text { Transition } \\
\text { variable }\left(\mathbf{S}_{t}\right)\end{array}$ & $\Delta y_{\mathrm{t}-1}$ & $\Delta y_{\mathrm{t}-3}$ & $\Delta y_{\mathrm{t}-4}$ & $\Delta y_{\mathrm{t}-2}$ & $\Delta y_{t-1}$ & $\Delta y_{\mathrm{t}-3}$ & $\Delta y_{\mathrm{t}-3}$ \\
\hline \multirow[t]{2}{*}{ Threshold (c) } & 0.040 & 0.003 & 0.010 & 0.021 & 0.017 & 0.013 & 0.006 \\
\hline & 0.000 & 0.000 & 0.079 & 0.009 & 0.000 & 0.000 & 0.509 \\
\hline \multirow[t]{2}{*}{$\begin{array}{l}\text { Speed of } \\
\text { transition }(\gamma)\end{array}$} & 24.444 & 20.760 & 3.304 & 4.585 & 3.944 & 26.378 & 26.210 \\
\hline & 0.651 & 0.168 & 0.162 & 0.202 & 0.003 & 0.311 & 0.000 \\
\hline \multicolumn{8}{|l|}{$\begin{array}{l}\text { Linear part: } \\
G\left(s_{t} ; \gamma, c\right)=0\end{array}$} \\
\hline \multirow[t]{2}{*}{$E R P T$} & 0.044 & 0.105 & 0.024 & 0.112 & 0.044 & 0.093 & 0.049 \\
\hline & 0.001 & 0.000 & 0.269 & 0.001 & 0.000 & 0.021 & 0.129 \\
\hline \multicolumn{8}{|l|}{$\begin{array}{l}\text { Nonlinear part: } \\
G\left(s_{t} ; \gamma, c\right)=1\end{array}$} \\
\hline \multirow[t]{2}{*}{$E R P T$} & 0.222 & 0.071 & 0.136 & 0.006 & 0.073 & 0.126 & 0.163 \\
\hline & 0.012 & 0.000 & 0.005 & 0.936 & 0.736 & 0.162 & 0.000 \\
\hline$R^{2}$ & 0.735 & 0.772 & 0.695 & 0.870 & 0.954 & 0.793 & 0.845 \\
\hline $\mathrm{SS} R_{\text {ratio }}$ & 0.812 & 0.681 & 0.819 & 0.859 & 0.414 & 0.737 & 0.730 \\
\hline$p J B$ & 0.466 & 0.364 & 0.081 & 0.005 & 0.000 & 0.000 & 0.000 \\
\hline$p L M_{A R(6)}$ & 0.1898 & 0.968 & 0.429 & 0.057 & 0.543 & 0.121 & 0.393 \\
\hline$p L M_{A R C H(6)}$ & 0.446 & 0.996 & 0.058 & 0.316 & 0.000 & 0.019 & 0.093 \\
\hline$p L M_{c}$ & 0.193 & 0.176 & 0.625 & 0.088 & 0.539 & 0.241 & 0.010 \\
\hline$p L M_{R N L}$ & 0.410 & 0.851 & 0.943 & 0.164 & 0.572 & 0.730 & 0.618 \\
\hline
\end{tabular}

(Note) Table 2 reports elasticities of ERPT into CPI inflation from the LSTR model. Numbers in parentheses are $p$-values of estimates. $R^{2}$ denotes the coefficient of determination and $\mathrm{SS} R_{\text {ratio }}$ is the ratio of sum of squared residuals between the LSTR model and the linear specification. The following rows correspond to the misspecification tests: $p j B$ are the $p$-values of Jarque-Bera normality test; $p L M_{A R(4)}$ are the $p$-values of the LM test of no error autocorrelation up to the fourth-order; $p L M_{A R C H(4)}$ are the $p$-values of the LM test of no ARCH effects up to the fourth-order; $p L M_{c}$ are the $p$-values of the LM test of parameter constancy; and $p L M_{R N L}$ is the $p$-values of the LM test of no remaining nonlinearity. 
Figure 1. Estimated transition functions and ERPT
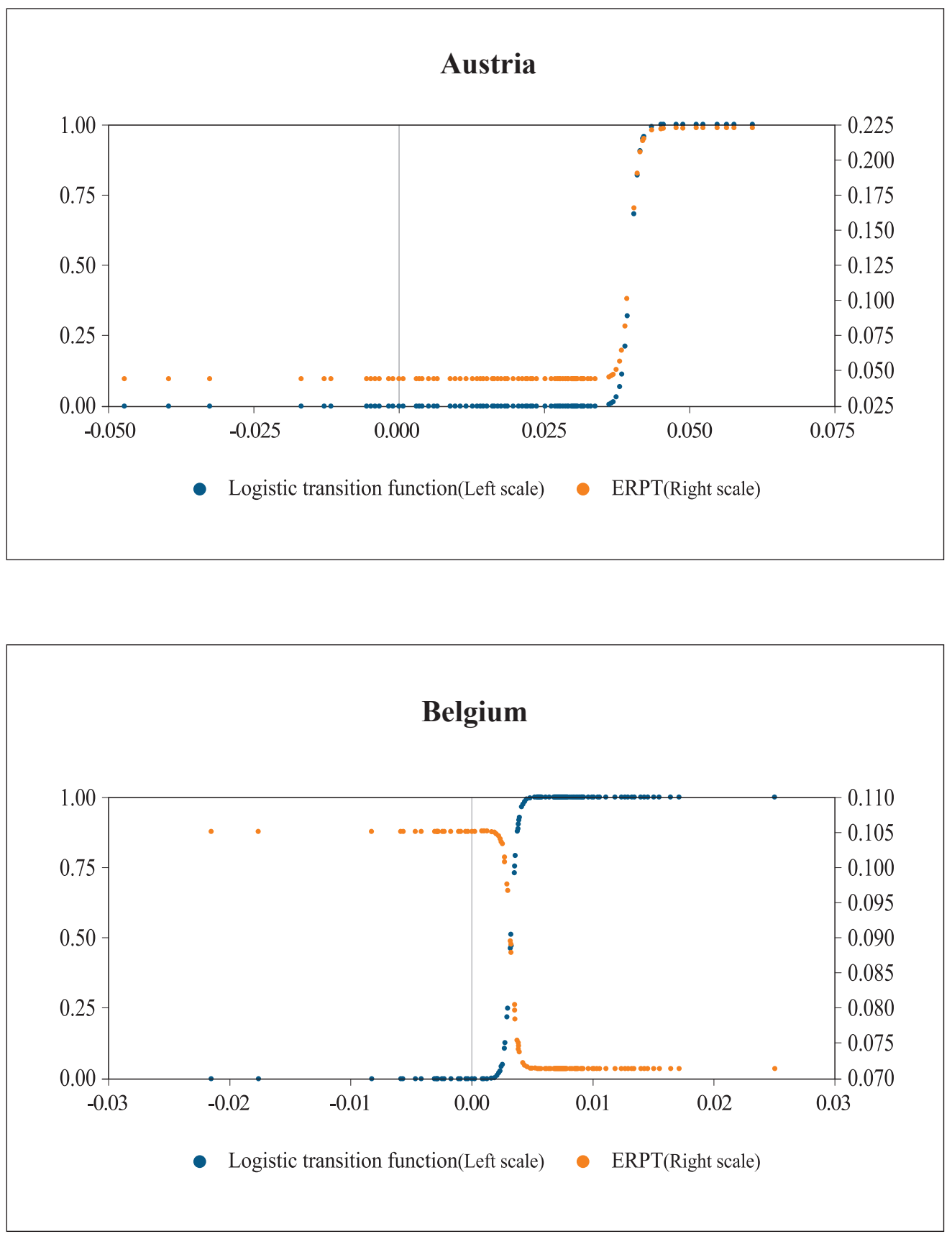
(continued)
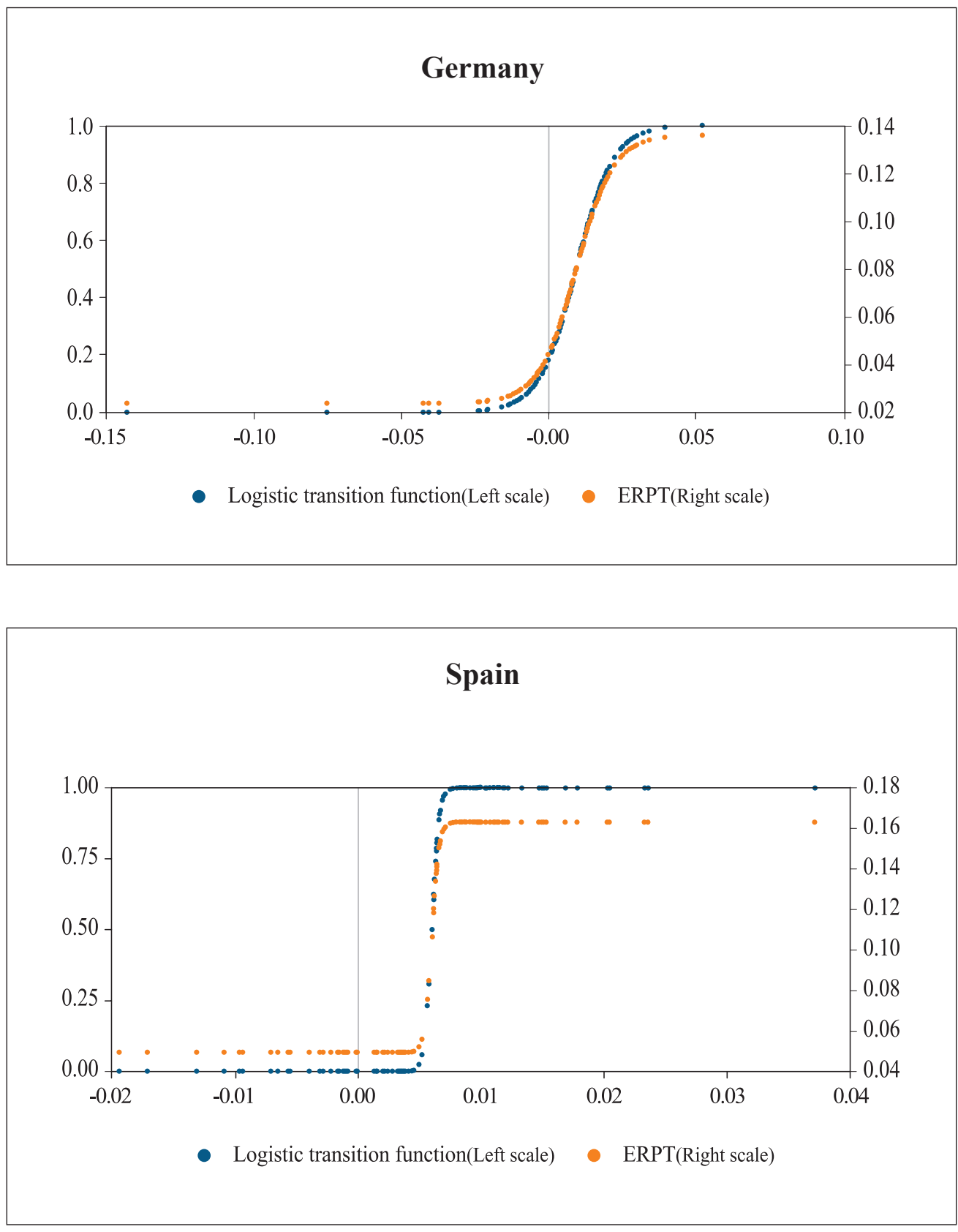

(Note) Estimated transition functions and ERPT as a function of past output growth. 
Figure 1 plots both the estimated transition functions and the ERPT as a function of the transition variable-lagged real GDP. As shown, the regime dependence of exchange rate transmission to business cycle is confirmed by the plots. The positive connection between the degree of the ERPT and real GDP growth is quite clear for three out of the four Euro member states. These results are consistent with the existing empirical literature dealing with the issue of nonlinearity. In their LSTR model, Nogueira Jr. and Leon-Ledesma (2008) found the same positive link between pass-through and economic activity. It is true for three out of the six inflation target countries. Similarly, in a Phillips curve threshold framework, Correa and Minella (2006) suggested that when the output gap is above a certain threshold, ERPT becomes higher in Brazil. Moreover, Goldfajn and Werlang (2000) provided evidence of the asymmetric behavior of ERPT over the business cycle in a panel of 71 countries. They found that depreciation has a higher pass-through to prices during periods of prosperity.

A significant negative link is also found between ERPT and output growth in Belgium. When real GDP growth is below some threshold, the extent of ERPT becomes higher (Figure 1). In fact, this is not surprising if low or negative output growth is seen as a period of economic slump or macroeconomic instability. If foreign producers expect less stable conditions in an importing country, then they may shift away from an LCP strategy, leaving their prices exposed to exchange rate fluctuations. As a result, ERPT would be higher in periods of macroeconomic distress than prosperity. It is worth stressing that Ben Cheikh and Rault (2016b) provided supportive evidence for this view. For five heavily indebted Euro area countries, namely, Greece, Ireland, Italy, Portugal, and Spain, they have confirmed that the increase in macroeconomic instability and the loss of confidence during the recent sovereign debt crisis resulted in higher sensitivity of domestic prices to exchange rate movements.

To give further insight on this plausible negative relationship, we plot time-varying ERPT coefficients over the period 1980 2015 (Figure 2). On the same graphs, we also report lagged real GDP growth and the estimated threshold level. According to Figure 2, the extent of pass-through was higher in Belgium during periods of contraction or recession. For example, we find an increasing rate of ERPT over the European Monetary System crisis (1992 1993) and the 2008 financial crisis. Due to macroeconomic 
instability episodes, it is more likely that foreign firms tend to modify their pricing strategy by choosing the exporter's currency pricing (PCP strategy) instead of the importer's currency pricing (LCP strategy). Therefore, it is not really surprising that pass-through would be greater in Belgium during these periods.

Figure 2. Time-varying ERPT and past output growth

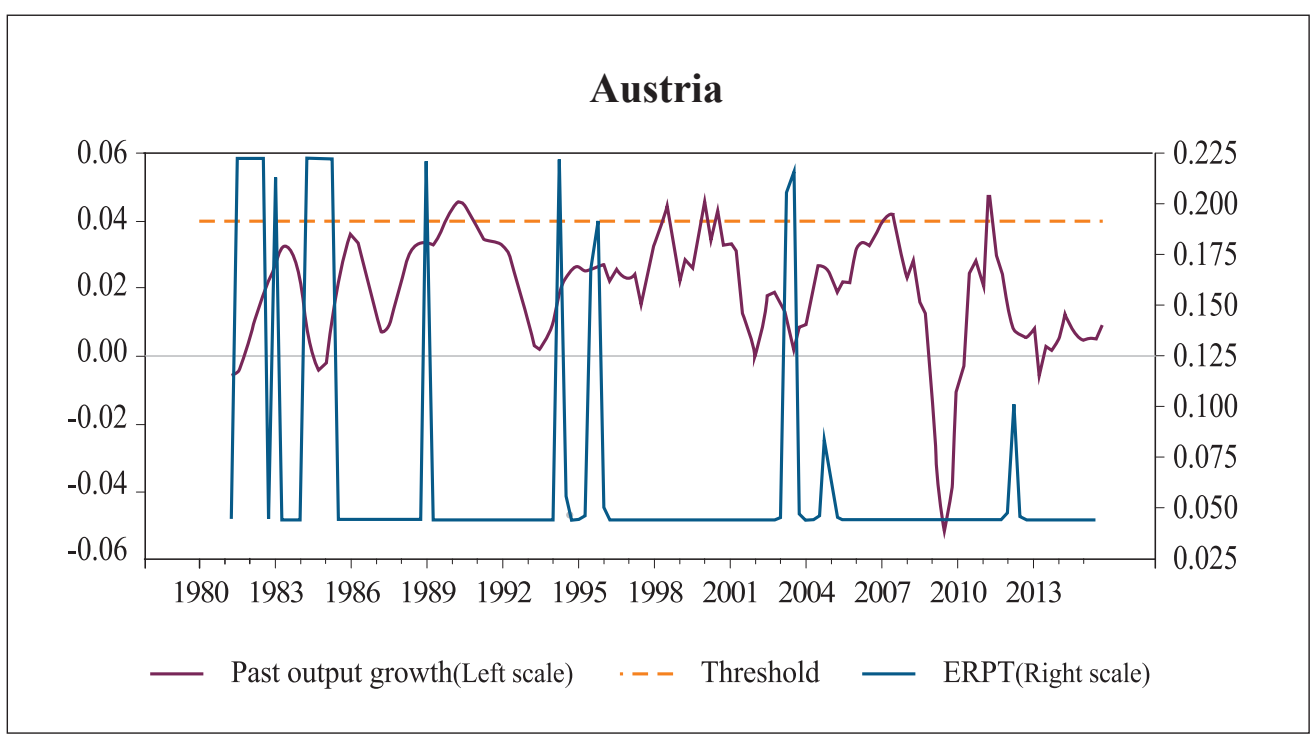

\section{Belgium}

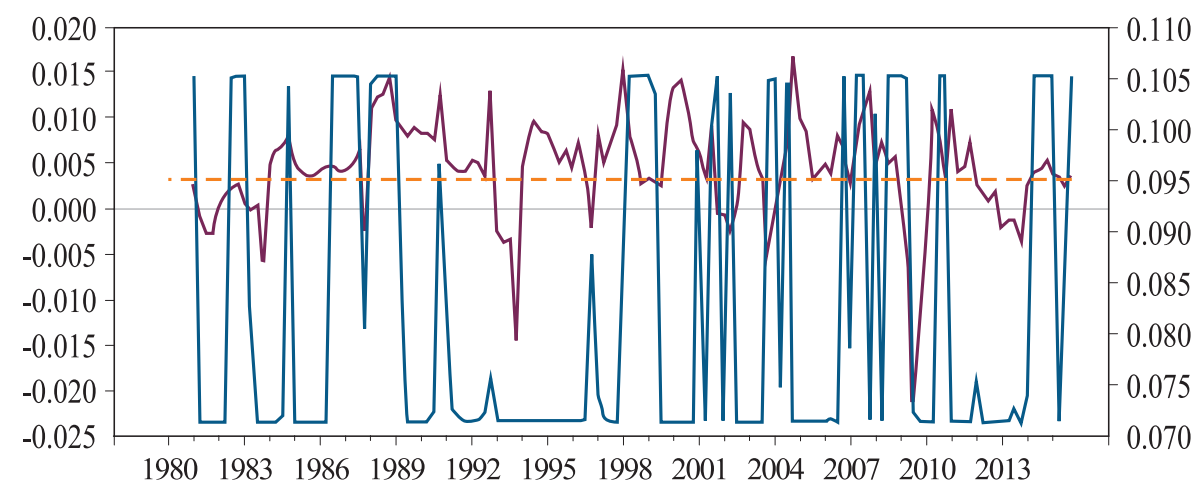

— Past output growth(Left scale) - - - Threshold — ERPT(Right scale) 
(continued)
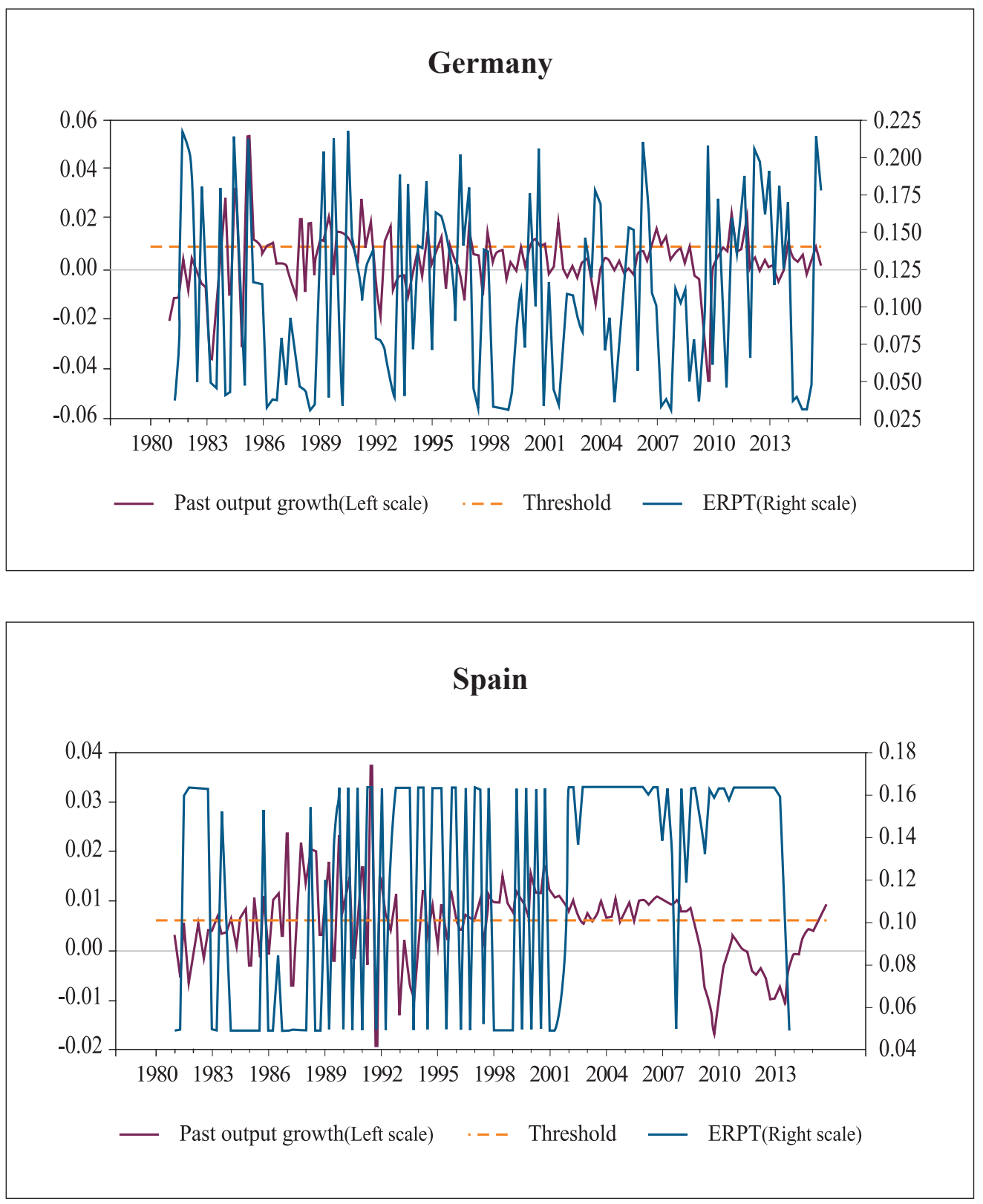

(Note) Time-varying ERPT and past output growth between 1980 and 2015. 
Overall, the results reveal the presence of regime dependence of ERPT with respect to the level of economic growth. We find that some Eurozone members have experienced larger ERPT during periods of expansion than in periods of recession. These findings are consistent with the fact that during periods of economic growth, firms can increase their markups without losing much market power. At the same time, these results should be interpreted with some caution as the pass-through cannot be related solely to the economic cycle. As for the case of Belgium, it is possible that other factors would influence the mechanism of ERPT during a recessionary period. Moreover, our empirical findings would have important implications for the design of monetary policy and the expectation of inflation in the Euro area. The differing impacts that economic activity has on the degree of passthrough should be considered carefully in policymaking. As ERPT is crucial in understanding inflation dynamics and its future path, neglecting the role of cyclical output would lead to inflation forecasting errors and, consequently, an inaccurate policy response. For the European monetary authorities, keeping sustained growth and stability within the Euro area would lead to relatively low and stable pass-through over time. In this case, there might be a positive feedback loop in the sense that declining ERPT would enhance business cycle synchronization, which in turn reduces inflation differentials within the monetary union.

\section{Conclusion}

This paper was aimed at providing empirical evidence on the nonlinearities in ERPT. Specifically, we explored the existence of nonlinearities with respect to the business cycle. Using quarterly data over the period of January 1980 April 2015, our results provide strong evidence of presence of nonlinearity in 7 out of 10 Eurozone countries. We show that the exchange rate transmission to inflation respond nonlinearly to the economic activity in the sense that ERPT is higher during expansion than recession periods. For instance, the pass-through coefficient in Germany is $0.02 \%$, which is not significantly different from zero when GDP growth is below $1 \%$, i.e., during an economic slowdown. However, when the German economy is growing faster, ERPT 
elasticity increases to about $0.13 \%$. The only exception was Belgium, where we found a negative link between ERPT and output growth. This is not surprising as low or negative output growth can be seen as a period of economic slump or macroeconomic instability. Our findings have important policy implications for the design of monetary policy and the synchronization of business cycles in the monetary union context. By monitoring the different growth patterns and how they affect pass-through, European monetary authorities would enhance inflation convergence within the Euro area.

Received 23 February 2018, Revised 10 April 2018, Accepted 1 May 2018

\section{References}

Aleem, A., and Lahiani, A. "A Threshold Vector Autoregression Model of Exchange Rate Pass-Through in Mexico", Research in International Business and Finance, 30, (2014): 24-33.

Andersson, M., Masuch, K., and Schiffbauer, M. "Determinants of inflation and price level differentials across the euro area countries", ECB Working Papers Series No. 1129, (2009).

Ben Cheikh, N. "Asymmetric exchange rate pass through in the Euro area: new evidence from smooth transition models", Economics, 6 (39), (2012): $1-28$.

Ben Cheikh N., and Louhichi W. "Revisiting the role of inflation environment in exchange rate pass-through: a panel threshold approach", Economic Modelling, vol. 52(PA), (2016): 233-238.

Ben Cheikh, N., and Rault, C. "The Role of the Business Cycle in Exchange 
Rate Pass-Through: The Case of Finland", Journal of Quantitative Economics, vol. 14(1), (2016): 15-27.

Ben Cheikh, N., and Rault, C. "The Pass-through of Exchange Rate in the Context of the European Sovereign Debt Crisis", International Journal of Finance \& Economics, 21(2), (2016): 154-166.

Campa, J., and Goldberg, L. "Exchange rate pass-through into import prices", The Review of Economics and Statistics, 87(4), (2005): 679-690

Ca'Zorzi, M., Kahn, E., and Sanchez, M. "Exchange rate pass-through in emerging markets", ECB Working Papers Series No. 739, (2007).

Comunale, M. and Kunovac, D. "Exchange rate pass-through in the euro area”, ECB Working Papers Series No. 2003, (2017).

Correa, A., and Minella, A. "Nonlinear mechanisms of exchange rate passthrough: a Phillips curve model with threshold for Brazil", Working Paper No. 122, Central Bank of Brazil, (2006).

Donayre, L., and Panovska, I. "State-dependent exchange rate pass-through behavior", Journal of International Money and Finance, 64(C), (2016): 170195.

Elliott, G., Rothemberg, T., and Stock, J. "Efficient tests for an autoregressive unit root", Econometrica, 64(4) (1996): 813-839.

Eitrheim, Ø., and Teräsvirta, T. "Testing the adequacy of smooth transition autoregressive models", Journal of Econometrics, 74 (1996): 59-76.

García, J., C. and Restrepo, J. "Price Inflation and Exchange Rate PassThrough in Chile", Working Paper No. 128, Central Bank of Chile, (2001).

Lin, P.-C., and Wu, C.-S. "Exchange rate pass-through in deflation: The case 
of Taiwan", International Review of Economics and Finance, 22, (2012): 101-111.

Lumsdaine, R. L., and Papell, D. H. "Multiple Trend Breaks and the Unit-Root Hypothesis", Review of Economics and Statistics, 79, No. 2, (1997) 212-218.

Marazzi, M., Sheets, N., Vigfusson, R., Faust, J., Gagnon, J., Marquez, J., Martin, R., Reeve, T., and Rogers, J. "Exchange Rate Pass-through to U.S. Import Prices: some New Evidence", International Finance Discussion Paper No. 832, Board of Governors of the Federal Reserve System, (2005).

McCarthy, J. "Pass-through of exchange rates and import prices to domestic inflation in some industrialized economies", Eastern Economic Journal, 33(4), (2007): 511-537.

Nogueira Jr., R. P., and Leon-Ledesma, M. "Exchange Rate Pass-Through Into Ination: The Role of Asymmetries and Nonlinearities", Studies in Economics No. 0801, Department of Economics, University of Kent, (2008).

Özyurt, S., "Has the exchange rate pass through recently declined in the euro area?", ECB Working Papers Series No. 1955, (2016).

Teräsvirta, T., "Specification, estimation and evaluation of smooth transition autoregressive models", Journal of the American Statistical Association, 89, (1994): 208-218.

van Dijk, D., Teräsvirta, T., and Franses, P. "Smooth Transition Autoregressive Models: A Survey of Recent Developments",. Econometric Reviews, 21: 1-47 (2002). 


\section{Appendix}

Table A1. Full estimation results from the LSTR model

\begin{tabular}{|c|c|c|c|c|c|c|c|}
\hline & Austria & Belgium & Germany & Greece & Italy & Portugal & Spain \\
\hline$S_{t}$ & $\Delta y_{\mathrm{t}-1}$ & $\Delta y_{\mathrm{t}-3}$ & $\Delta y_{\mathrm{t}-4}$ & $\Delta y_{\mathrm{t}-2}$ & $\Delta y_{\mathrm{t}-1}$ & $\Delta y_{\mathrm{t}-3}$ & $\Delta y_{\mathrm{t}-3}$ \\
\hline \multirow[t]{2}{*}{$c$} & 0.040 & 0.003 & 0.010 & 0.021 & 0.017 & 0.013 & 0.006 \\
\hline & 0.000 & 0.000 & 0.079 & 0.009 & 0.000 & 0.000 & 0.509 \\
\hline \multirow[t]{2}{*}{$\gamma$} & 24.444 & 20.760 & 3.304 & 4.585 & 3.944 & 26.378 & 26.210 \\
\hline & 0.651 & 0.168 & 0.162 & 0.202 & 0.003 & 0.311 & 0.000 \\
\hline \multicolumn{8}{|c|}{ Linear part: $G=0$} \\
\hline \multirow[t]{2}{*}{ Constant } & 0.002 & 0.009 & 0.007 & 0.001 & 0.001 & 0.006 & 0.000 \\
\hline & 0.193 & 0.000 & 0.000 & 0.603 & 0.094 & 0.091 & 0.960 \\
\hline \multirow[t]{2}{*}{$\Delta c p i_{\mathrm{t}-1}$} & & & 0.352 & & 0.388 & 0.151 & \\
\hline & & & 0.004 & & 0.000 & 0.076 & \\
\hline \multirow[t]{2}{*}{$\Delta c p i_{t-2}$} & 0.197 & & & & & 0.293 & 0.091 \\
\hline & 0.007 & & & & & 0.003 & 0.553 \\
\hline \multirow[t]{2}{*}{$\Delta c p i_{t-3}$} & & & & & 0.233 & & \\
\hline & & & & & 0.000 & & \\
\hline \multirow[t]{2}{*}{$\Delta c p i_{t-4}$} & 0.538 & 0.425 & 0.167 & 0.728 & 0.206 & 0.308 & 0.765 \\
\hline & 0.000 & 0.000 & 0.273 & 0.000 & 0.001 & 0.000 & 0.000 \\
\hline \multirow[t]{2}{*}{$\Delta e_{t}$} & 0.044 & 0.105 & 0.024 & 0.112 & 0.044 & 0.093 & 0.049 \\
\hline & 0.001 & 0.000 & 0.269 & 0.001 & 0.000 & 0.021 & 0.129 \\
\hline \multirow[t]{2}{*}{$\Delta e_{t-1}$} & & & & 0.046 & 0.013 & & 0.056 \\
\hline & & & & 0.294 & 0.334 & & 0.032 \\
\hline \multirow[t]{2}{*}{$\Delta e_{t-2}$} & & 0.058 & & & & 0.041 & -0.077 \\
\hline & & 0.007 & & & & 0.146 & 0.023 \\
\hline \multirow[t]{2}{*}{$\Delta e_{t-3}$} & & 0.025 & & & & & \\
\hline & & 0.044 & & & & & \\
\hline \multirow[t]{2}{*}{$\Delta e_{t-4}$} & 0.006 & & 0.019 & & & 0.041 & \\
\hline & 0.685 & & 0.477 & & & 0.129 & \\
\hline \multirow[t]{2}{*}{$\Delta w_{t}^{*}$} & 0.084 & 0.168 & 0.028 & 0.186 & 0.103 & 0.155 & 0.125 \\
\hline & 0.000 & 0.012 & 0.445 & 0.000 & 0.000 & 0.016 & 0.002 \\
\hline
\end{tabular}


(continued)

\begin{tabular}{|c|c|c|c|c|c|c|c|}
\hline & Austria & Belgium & Germany & Greece & Italy & Portugal & Spain \\
\hline \multirow[t]{2}{*}{$\Delta w_{t-1}^{*}$} & 0.016 & -0.067 & & 0.101 & 0.008 & 0.000 & \\
\hline & 0.256 & 0.090 & & 0.100 & 0.729 & 0.995 & \\
\hline \multirow[t]{2}{*}{$\Delta w_{t-2}^{*}$} & & 0.171 & 0.039 & & & & -0.046 \\
\hline & & 0.000 & 0.154 & & & & 0.376 \\
\hline \multicolumn{8}{|l|}{$\Delta w_{t-3}^{*}$} \\
\hline & & & & & & & \\
\hline \multirow[t]{2}{*}{$\Delta w_{t-4}^{*}$} & -0.001 & & 0.051 & & & & \\
\hline & 0.982 & & 0.279 & & & & \\
\hline \multirow[t]{2}{*}{$\Delta y_{t}$} & 0.027 & -0.389 & & -0.025 & & & 0.565 \\
\hline & 0.642 & 0.016 & & 0.605 & & & 0.001 \\
\hline \multirow[t]{2}{*}{$\Delta y_{t-1}$} & & & 0.006 & & 0.042 & & \\
\hline & & & 0.839 & & 0.528 & & \\
\hline \multirow[t]{2}{*}{$\Delta y_{t-2}$} & 0.079 & & & & & & \\
\hline & 0.085 & & & & & & \\
\hline \multirow[t]{2}{*}{$\Delta y_{t-3}$} & & & -0.041 & & -0.011 & 0.014 & \\
\hline & & & 0.145 & & 0.848 & 0.957 & \\
\hline \multirow[t]{2}{*}{$\Delta y_{t-4}$} & & & -0.078 & 0.059 & & 0.370 & \\
\hline & & & 0.328 & 0.203 & & 0.077 & \\
\hline \multicolumn{8}{|c|}{ Linear part: $G=1$} \\
\hline \multirow[t]{2}{*}{$\Delta e_{t}$} & 0.178 & 0.057 & 0.112 & -0.105 & 0.029 & 0.032 & 0.114 \\
\hline & 0.046 & 0.645 & 0.052 & 0.258 & 0.895 & 0.743 & 0.010 \\
\hline \multirow[t]{2}{*}{$\Delta e_{t-1}$} & & & & 0.023 & -0.321 & & -0.060 \\
\hline & & & & 0.774 & 0.213 & & 0.066 \\
\hline \multirow[t]{2}{*}{$\Delta e_{t-2}$} & & -0.034 & & & & 0.080 & 0.069 \\
\hline & & 0.300 & & & & 0.299 & 0.151 \\
\hline \multirow[t]{2}{*}{$\Delta e_{t-3}$} & & -0.029 & & & & & \\
\hline & & 0.275 & & & & & \\
\hline \multirow[t]{2}{*}{$\Delta e_{t-4}$} & -0.139 & & -0.068 & & & 0.114 & \\
\hline & 0.042 & & 0.232 & & & 0.159 & \\
\hline
\end{tabular}

(Note) Table A1 reports estimates of the LSTR pass-through equation. Numbers in parentheses are $p$-value. 